\title{
Entrevista a Evelyn Arizpe sobre culturas letradas subversivas, lectura de imágenes e inclusión
}

Concepción López Andrada *, Aldo Ocampo González ${ }^{* *}$

Evelyn Arizpe es catedrática de la Universidad de Glasgow en la Escuela de Educación donde inició el Magíster Children's Literature and Literacies y ahora coordina un nuevo magíster Erasmus Mundus Children's Literature, Media and Culture, junto con otras cuatro universidades europeas. Supervisa a estudiantes de doctorado que trabajan en literatura infantil y lectura. Su docencia e investigación establece puentes entre la literatura infantil y la educación, campo en torno al cual ha trabajado ampliamente en los últimos años. Concretamente, Arizpe ha estudiado e investigado la lectura y las respuestas lectoras, involucrando tanto a niños como a adolescentes en diversos contextos internacionales. Entre otros libros, es coautora de Reading lessons from the eighteenth century (2006); Visual journeys through wordless narratives (2014) y es coeditora de Young people reading: Empirical research across international contexts (2018). Sus proyectos más recientes se centran en la relación entre migración, xenofobia y creación de espacios seguros a través de la lectura del libro-álbum o el álbum ilustrado y de prácticas artísticas y creadoras. Estos proyectos se han realizado en colaboración con gobiernos y ONGs de Escocia, México y Egipto, iniciativas financiadas con las ayudas del Arts and Humanities Research Council Global Challenges Research Fund

Directora del Observatorio sobre Educación Lectora, Nuevas Ciudadanías y Educación Lectora "Emilia Ferreiro" (Centro de Estudios Latinoamericanos de Educación Inclusiva, CELEI, Chile). Profesora de la Universidad de Extremadura (UEX, España). clopezc@unex.es

** Director del Centro de Estudios Latinoamericanos de Educación Inclusiva (CELEI, Chile). Doctor en Ciencias de la Educación, Universidad de Granada (UGR, España). aldo.ocampo@celei.cl 
(AHRC-GCRF) y European Social Fund y Scottish Funding Council. Actualmente es presidenta de la International Research Society for Children's Literature (IRSCL).

Doctora Arizpe, quisiéramos agradecer su apoyo y disposición para participar de esta publicación. Nos gustaría comenzar con las siguientes preguntas:

Considerando la relevancia de sus trabajos de investigación: ¿Podríamos hablar de un nuevo campo en relación con las "políticas de la mirada" y de la "lectura de imágenes" que en el contexto digital se revelan imprescindibles? ¿Cuál sería el estado actual de estos estudios en su opinión? ¿Qué encrucijadas emergen en el presente a través de este campo de estudio en relación con las culturas letradas?

Les agradezco mucho a ustedes, Concepción y Aldo, por su interés en mi investigación y por su invitación a participar en este ciclo de entrevistas.

Para comenzar a responder a estas preguntas, quisiera anotar que podría discutirse si realmente el campo puede designarse como "nuevo", ya que las "políticas de la mirada" y la "lectura de imágenes" podría decirse que surgen a la par del nacimiento del arte y de la presencia de códigos simbólicos y estéticos en la comunicación entre seres humanos. Como bien sabemos, los creadores se valen de una serie de herramientas y recursos culturales, estéticos y poéticos, entre otros, para posicionar de cierta manera al que mira la imagen. Esto me recuerda el comentario de una niña de ocho años que entrevisté en el primer proyecto de investigación en el que Morag Styles y yo nos adentramos en el mundo del libro-álbum y sus lectores. El objetivo del proyecto "Lectura de imágenes" (2000-2003) consistió indagar acerca de la respuesta de niñas y niños lectores de entre 4 y 11 años ante una selección de libros-álbum cuyos códigos estéticos, simbólicos y lúdicos invitaban a un acto de mirar más allá de la superficie. Ante la pregunta de ¿cómo sabes leer una imagen? esta niña se refirió a los vitrales en las iglesias, comentando que los mira e intenta contar las historias y cómo esto le ayuda a "entender los dibujos" en los libros (Arizpe y Styles, 2004, p. 82). Su respuesta nos remite a la época medieval cuando las historias bíblicas se transmitían a las personas analfabetas a través de las imágenes en los vitrales. De tal 
forma que en ese estudio encontramos que los niños y niñas se valen de sus experiencias y conocimientos para hacer su propia "lectura de imágenes".

Nuestra investigación (y otras que le siguieron) reveló que la mayoría de las niñas y niños puede interpretar imágenes sofisticadas; de igual modo también fue claro que no todos llegan a apreciar los múltiples niveles de significado que ofrece la interacción entre la palabra y la imagen en los libros-álbum más complejos (y por cierto, tampoco todos los adultos, como por ejemplo, los maestros). Muchos lectores requieren de un soporte para mirar más de cerca. Por ello, con mis colegas en la Universidad de Glasgow, hemos desarrollado una serie de herramientas - teóricas, metodológicas y didácticas-para identificar, interpretar y comprender cuál es esa perspectiva que se nos invita a tomar y cómo podemos crear una distancia del objeto estético y mirar o "leer" desde un espacio más crítico, más enriquecedor. Este acercamiento analítico y pedagógico a las "políticas de la mirada" es una actividad cada vez más imprescindible, como bien dicen ustedes, porque en el contexto digital contemporáneo las imágenes no solamente se reproducen y comunican con una rapidez nunca antes vista, sino que también pueden manipularse con facilidad (pensemos en las posibilidades de Photoshop, las noticias falsas y la inmediatez de la información visual en las redes sociales).

Entonces, a pesar de que no podemos decir que es un campo "nuevo", lo que sí es novedoso es el área de estudios desde la estética, la literatura y la educación y de cómo los niños y los jóvenes interpretan y comprenden imágenes, especialmente, los estudios que toman en cuenta lo que ellos mismos dicen y opinan. Hasta hace relativamente poco tiempo no se les otorgaba importancia a estas respuestas, porque se consideraban no solamente inmaduras sino hasta "peligrosas", porque podían relegar la cuestión del "buen gusto" a quienes no se consideraban lo suficientemente educados para hacerlo. A pesar de que esto sigue siendo el caso en muchos contextos culturales y educativos, en otros se ha aceptado la idea de que los niños y jóvenes tienen el derecho de seleccionar lo que miran y leen, así como a expresar sus opiniones acerca de ello y que estas opiniones tienen validez. A la par, el mercado editorial de libros para niños y jóvenes, con todas las opciones visuales que ofrece, ha experimen- 
tado un crecimiento sustancial desde el comienzo del milenio. La aportación creativa de los ilustradores es cada vez más reconocida con premios y exposiciones en ferias y festivales (pensemos, por ejemplo, en las ferias internacionales de Guadalajara o Boloña y, por supuesto, en las ferias específicas del libro infantil y juvenil). Por lo mismo, también ha aumentado el interés y el número de investigaciones referidas a la respuesta lectora, tanto ante la palabra como ante la imagen, dentro y fuera de la escuela. Es un campo dinámico debido a que los objetos y sujetos de estudio se renuevan constantemente (me refiero a las nuevas obras y a las nuevas generaciones de niños). También es un campo con oportunidades para la investigación interdisciplinaria (desde la neurociencia y la psicología hasta la historia del arte y los estudios de los medios de comunicación); el estado actual de los estudios revela un gran potencial en cuanto a lo que estamos aprendiendo en relación con la diversidad, la inclusión, la empatía, la lectura literaria y otros temas cruciales para la educación, además de las líneas de investigación que incorporan los textos digitales.

Volviendo a la investigación que se publicó con el Fondo de Cultura Económica en español en 2004 (Serie Espacios para la lectura), quiero mencionar que Morag Styles y yo partimos de las teorías de la recepción, representadas por pensadores tanto de la crítica literaria - como Wolfgang Iser-, como desde la educación, sobre todo Louise Rosenblatt (publicada en esa misma serie del FCE). A grandes rasgos, estas teorías sostienen que la obra no existe sin el lector y, de hecho, es el lector quien crea o recrea la obra durante el acto de leer. Morag y yo estábamos interesadas en la recepción y recreación no solamente del texto, sino también de la imagen y, sobre todo, de la coyuntura entre ambos. Nosotras mismas estábamos fascinadas e intrigadas por el libro-álbum, entendido como objeto estético y cultural donde los creadores juegan no solamente con la interacción entre la palabra y la imagen, sino también con otras modalidades del libro. Nos inquietaba la cuestión de cómo los niños podrían comprender e interpretar esos libros-álbum complejos donde pueden encontrarse elementos "posmodernos" o "subversivos", como la fragmentación y la ironía, así como referentes intertextuales o ambiguos. Así nació el proyecto "Lectura de imágenes" y desde entonces casi toda mi investigación se ha desarrollado dentro este campo, con trabajos que involucran 
distintas poblaciones lectoras y diversos espacios de lectura, incluidos los contextos históricos

Por supuesto que son muchas las encrucijadas a propósito de las culturas letradas, y algunas de ellas se remiten a percepciones que persisten desde hace años. A la palabra escrita se le continúa atribuyendo una autoridad o peso mayor que a la imagen, quizá porque es necesario tener algo de educación para poder decodificar las letras, mientras que se piensa que cualquiera puede "ver" una imagen. Se ha establecido también la convicción de que los libros para niños sin imágenes son más serios, es decir, que los libros con imágenes son meramente para niños pequeños, para entretener a los que todavía no saben leer. Ligado a ello está la idea de que cuando hay imágenes, estas existen como mera decoración o como soporte para la palabra y tienen poco que aportar por sí solas. Todas estas convicciones y expectativas continúan saltando a la vista, no solamente en las investigaciones referidas a la respuesta lectora de muchos niños y jóvenes, sino también en las perspectivas de maestros y bibliotecarios, mamás y papás, quienes se muestran incómodos con la idea de leer la imagen y que esa imagen pueda aportar tanto o más que las palabras.

Sin embargo, pienso que cada vez más los libros-álbum y otros textos con dimensiones multimodales — donde la imagen, el diseño y los paratextos son íntegros al significado- comienzan a rebatir estas ideas y a exigir un público lector que no solamente sabe decodificar letras, sino también imágenes, un público-como me gusta nombrarlo-, con una "mirada perspicaz". Forman parte de esta mirada la selección y el rechazo, los tiempos y espacios de la lectura, la interpretación y el diálogo. Muchas veces las obras mismas son las que van guiando a ese público, ofreciendo distintas invitaciones a leer y mirar. Además, frente a la lectura en pantalla ha aumentado el interés en el libro como objeto material y en el comprender cómo su materialidad interactúa con la corporalidad y afectividad del lector abriendo nuevas posibilidades para la interpretación y la transformación. Las nuevas generaciones están más abiertas a estas posibilidades y, por lo tanto, resulta obvio que trabajar juntos para desarrollar esa mirada perspicaz representa una oportunidad tanto para los adultos como para los jóvenes. 


\section{¿Qué elementos son centrales en el estudio del derecho a la lectura y de la mediación lectora, en tanto práctica crítica, radical y contingente?}

Las investigaciones que he llevado a cabo se sustentan en las ideas arriba mencionadas y que apoyan los derechos del lector, pero me parece que uno de esos derechos es precisamente el derecho de la niña, el niño o el joven lector a valerse de una guía o mediador. Michèle Petit expone que para que las palabras de la literatura, el lenguaje del arte o el de la ciencia hagan al mundo más habitable son necesarias otras palabras, las de un facilitador que te acoja, te escuche y que sueñe el mundo contigo.

Ciertamente, también tienen el derecho a rechazar el acompañamiento a su lectura, pero este derecho es fundamental en el caso de los que se sienten menos seguros como lectores, los que necesitan algo de ayuda para seleccionar, decodificar o para expresarse acerca de lo que leen. En otras palabras, la mayoría de quienes están aprendiendo el oficio de lector requiere un soporte, a veces mayor, a veces menor, por parte de un lector con más experiencia. La importancia de un guía ha sido recalcada en muchas de las entrevistas que he llevado a cabo con lectores de distintas edades; los lectores con frecuencia se refieren a la intervención crucial de un familiar, una maestra o un amigo, que recomendó un texto, con quien se sostuvo un diálogo y a veces el resultado fue el enganche con la lectura. Ese acompañamiento es esencial sobre todo en situaciones donde los lectores no poseen las herramientas básicas para acercarse a un texto, cuando desconocen el idioma del texto o no saben leer y, como ya mencioné, también puede ser un soporte para desarrollar la lectura de imágenes.

El diálogo que conlleva el intercambio de experiencias, saberes y opiniones puede tener una gran influencia en la formación y la trayectoria de un lector. Un buen mediador conocerá la oferta existente y reconocerá los libros con el potencial de atraer e involucrar a un lector debido a sus características o por su situación. Al tener en mente los criterios de selección y las formas de interacción con los textos ( $\sin$ olvidar las imágenes), sin perder de vista los derechos y la libertad del lector, el mediador participa en lo que ustedes describen como una "práctica crítica, radical y contingente". La práctica crítica, desde mi punto de vista, involucra la apertura de distintos mundos: tomar dis- 
tancia para profundizar en la experiencia estética, pero también para comenzar a comprender las herramientas que utiliza el creador para crear significados, desde el diseño hasta las figuras retóricas.

A través de una mirada analítica, la práctica crítica incorpora una reflexión relacionada con la inclusión a través de interrogar al texto acerca de quiénes están representados allí, las imágenes y cómo (y quiénes permanecen invisibles). Por esto mismo, la práctica es radical: tiene que ver con tomar riesgos con la selección, apostar por el potencial de los textos complejos, la capacidad del lector, un diálogo donde se valen múltiples interpretaciones y por la subversión de los textos y las tradiciones didácticas que excluyen o ignoran a ciertos grupos. Otra idea radical es reflexionar en torno al libro objeto y cómo existe en el mundo, es decir, pensar que la lectura implica no solamente las conexiones que el lector tiene con el mundo, sino también las conexiones que el libro tiene como objeto material, con las formas de producción y con los espacios de lectura. Esta atención al libro como producto cultural, social e ideológico es fundamental para realizar una práctica crítica y nos conduce a la idea de la práctica contingente.

Esta última toma en cuenta los antecedentes culturales y sociales del lector y los valora. A partir de estos antecedentes se buscan libros relevantes que respondan a las circunstancias que rodean al lector. Esto implica una sensibilidad a los contextos, la búsqueda de lecturas y actividades apropiadas; por ejemplo, para momentos lúdicos o para momentos de crisis. En la investigación “Travesías visuales” que realizamos entre colegas en Arizona, Barcelona, Boloña y Sídney, utilizando Emigrantes (2006) de Shaun Tan con grupos de niños migrantes, aprendimos lo valioso que era para estos lectores poder expresarse sobre sus experiencias, pero sobre todo reconstruir su identidad y su historia a través de la lectura, el diálogo y otras actividades relacionadas con el tema (Arizpe,2012, p.44-68; Arizpe, Colomer y Martínez-Roldán 2014 , p. 103.). Más recientemente, en una serie de entrevistas que realizamos a mediadores de lectura durante el sismo de 2017 en México, nos percatamos de la importancia de la experiencia del mediador en estas circunstancias para ofrecer lecturas adecuadas a los grupos afectados. En otras palabras y, para resumir, el elemento más importante en el estudio y la práctica alrededor de la lectura son los lectores y todo lo demás debe girar en torno a ellos. 


\section{¿Cuáles son, a su juicio, las principales ideas que podrían sustentar la formación de los trabajadores culturales para fomentar una intervención cultural en el marco de la inclusión y la justicia social?}

Mi respuesta parte de la propuesta de utilizar la literatura y el arte y, sobre todo la literatura infantil y juvenil (LIJ), para la intervención cultural y, volviendo a la pregunta anterior, incluye también un llamado a una reflexión crítica por parte del trabajador social o mediador. A partir de mi investigación, pero también desde los estudios de colegas que para mí han sido fundamentales, sugiero cinco de las principales ideas que deben sustentar la formación y el proceso de intervención: en primer lugar, es esencial conocer bien el contexto donde se llevará a cabo la intervención cultural. Esto implica apoyarse en la cultura tangible e intangible de los espacios o de los individuos, incluir diversas voces y reconocer lo que podemos llamar la "mochila cultural" que incluye los "fondos de conocimiento" (funds of knowledge) (García, Amanti, Neff, González1992, p. 132-141) que todos llevamos con nosotros. Es decir que el mediador o trabajador cultural debe estar atento al potencial de los saberes de los individuos y grupos y no caer en una visión de déficit (y tampoco de lástima);por ejemplo, porque un lector no conoce la lengua del texto, no sabe leer y escribir o se encuentra en condiciones vulnerables.

En segundo término, junto con el conocimiento del contexto, es importante conocer bien los libros que se tienen a la mano, por pocos o muchos que estos sean, para poder seleccionar los más adecuados. Idealmente, y cuando hay presupuesto, esta selección se puede enriquecer si se incluye una gama de libros diversos, por ejemplo, libros multilingües, libros-álbum sin palabras y libros de no-ficción junto con una gama de temas. Al hacer la selección, es esencial tener los objetivos claros y reconocer, como dice Colomer (2005, p. 138)cuáles son los discursos que se presentan en los textos elegidos.De acuerdo con las circunstancias, pueden incluirse temas más complejos, como la migración o el cambio climático. Ya he mencionado que es importante considerar la forma en que se representan la inclusión y la justicia social en el texto mismo, estar atentos al género de los protagonistas y al rol de las mujeres y hombres que aparecen, como también a la presencia de minorías en cuanto a culturas, discapacidades y sexualidad. Es im- 
portante también que la selección no se imponga, sino que dentro de lo posible, los lectores tengan agencia para decidir lo que quieren leer o escuchar.

Un tercer principio, quizá bastante obvio, es valerse de distintas formas de aproximarse al texto y a las imágenes, y de actividades para extender la lectura. Pueden encontrarse muchas sugerencias en línea recomendadas por organizaciones dedicadas a la promoción o animación de la lectura ${ }^{1}$. Sin embargo, es necesario hacer una reflexión primero para adaptarlas según las circunstancias y, eso sí que es importante, reconocer que no se trata de aplicar terapias o de alimentar esperanzas falsas, especialmente en contextos críticos.

Un cuarto principio es reconocer que un libro puede funcionar de distintas maneras en la conexión con nosotros mismos y con el mundo que nos rodea. Una metáfora que nos ha servido tanto en cursos teóricos como en la práctica y que fue la base del programa "Leer con migrantes" (creado para la Secretaría de Cultura en México en la anterior administración, véase Para leer en contextos adversos y otros espacios emergentes, 2018) fue propuesta por la profesora americana Rudine Sims Bishop (1990). Ella sugiere considerar la LIJ puede funcionar como espejo, ventana y/o puerta. Como espejo, sugiere que a través del proceso de lectura los lectores pueden reconocerse en los libros, pero también ver nuevas representaciones de sí mismos, conduciendo quizá a una mayor comprensión de su propia cultura, dotando a sus experiencias de mayor significado y creando enlaces entre su presente y el pasado. Como ventana, en tanto, el libro permite al lector atisbar mundos alternativos y posibles al fomentar una nueva comprensión de los demás junto con la idea de vivir en un mundo diverso y complejo. Los lectores pueden comparar lo que ven por la ventana con lo que ven en el espejo y percibir contrastes entre sus creencias y valores y los que aparecen retratados en el texto. La puerta, por último, puede interpretarse como la frontera entre lo imaginario y lo real: al pasar de uno a otro lado, el lector se abre al mundo, quizá tomando un paso hacia la transformación y la acción ante las desigualdades y retos que percibe en ese mundo.

Pueden encontrarse algunas dentro de nuestra página www.childslitspaces.com para contextos de desplazamiento, bajo la sección de "Herramientas". 
Finalmente, un quinto principio es procurar crear un espacio donde se privilegie la experiencia poética, lúdica e inclusiva. Michèle Petit ha escrito mucho acerca del tema de la lectura y la transmisión cultural y no voy a repetir sus ideas aquí, pero estas han tenido un gran impacto en mi trabajo. Ella insiste en la importancia de provocar la imaginación, la memoria, el juego, y el diálogo e intercambio para ayudar a los que participan en esos espacios a encontrar su voz y poseer la palabra, con el fin de darle sentido y valor poético a sus experiencias vividas y, a partir de ahí, hacerles un lugar a las experiencias de los otros (Petit, 2015, p. 32 . Este principio resume mucho de lo que ya he dicho anteriormente, ya que nos remite de nuevo al acompañamiento sensible de los mediadores, a la selección de textos que inviten a conocer otros mundos, a la creación de un ambiente acogedor y abierto, y a la importancia de respetar los tiempos, conocimientos y necesidades de los participantes, sobre todo si se encuentran en contextos críticos o emergentes.

Quiero aclarar que no estoy segura de si todos estos son "principios" ni tampoco de existe un número determinado, pero para terminar esta sección quisiera recalcar la importancia de extender y profundizar las capacidades y conocimientos de los trabajadores y mediadores a través de herramientas teóricas y también de investigación. Esto les permitirá comprender mejor quiénes son los lectores y cuáles son sus historias (por ejemplo, las causas de la migración); qué sucede en el acto de la lectura y la experiencia estética; cómo funcionan las palabras, las imágenes y la relación entre ambas (y por lo tanto cuál puede ser el potencial del libro-álbum, la novela gráfica, el comic e incluso textos e imágenes en pantalla) y, finalmente, conocerse mejor a sí mismos como trabajadores culturales, pero también como lectores. Todo ello ayudará a sustentar su vocación por la inclusión y la justicia social y el uso de la LIJ y otras manifestaciones culturales y artísticas para contribuir a su trabajo en estas áreas.

\section{¿Qué retos nos encontramos como docentes, investigadores} y ciudadanos a la hora de revisar muchas de las visiones anquilosadas y conservadoras respecto de la didáctica de la LIJ? Los mayores retos tienen muchos años anclados en la didáctica y ya mencioné algunos de ellos en la primera pregunta, cuando me referí a las ideas conservadoras que perduran acerca de la lectura de imá- 
genes. Aquí incluyo las visiones anquilosadas no solamente de la LIJ, sino también de la literatura en general. Además de crear un canon que contiene poca literatura contemporánea o LIJ, el currículo tiende a mirar la literatura y los libros como objetos sagrados que no pueden cuestionarse o criticarse. El "mensaje" del autor, descifrado por quienes se consideran con la autoridad para hacerlo (los maestros), es transmitido a los alumnos y no se acepta que pueda haber más que una sola verdad. En mi investigación incluso los jóvenes lectores piden la confirmación de que su interpretación es la "correcta”, porque así se les ha enseñado a pensar.

La otra cara de la moneda es el poco valor que se atribuye a la LIJ como literatura "seria". Ya mencioné que en los reducidos espacios donde existen los libros en el aula, los tiempos para su lectura son considerados como ratos de esparcimiento, no de aprendizaje. Por supuesto que son necesarios los ratos de lectura que no implican el aprendizaje, pero estos mismos libros, de entrada atractivos para los lectores, pueden leerse en el aula con la misma atención que una obra para adultos y a partir de ella pueden enseñarse - quizá de una forma más amable-, elementos literarios, recursos de la narrativa y también de la estética, desde la metáfora hasta la ironía y la metaficción. Lo ha venido argumentando la investigadora Teresa Colomer durante más de dos décadas: la LIJ contribuye al aprendizaje literario y, por lo tanto, es indispensable que los que trabajan en el ámbito educativo conozcan el potencial de esta literatura

Para reforzar este aprendizaje de una manera amena y divertida, por ejemplo, existen muchas obras en la LIJ que reflexionan en torno a la lectura y los libros ${ }^{2}$, que introducen al lector en la metaficción de una forma divertida y los invitan a conocer esos mundos a través del texto y la imagen. Son lecturas que más adelante pueden conducir a otras obras literarias como El Quijote.

¿Por qué no incorporar en la enseñanza una reflexión de los mismos lectores referida la lectura? ¿Por qué no explorar la historia que el libro y el papel juegan en la sociedad contemporánea, tomando en cuenta lo que ofrecen las pantallas digitales? ¿Por qué no permitir a

Este es el caso de Los cuadernos del doctor Calamar, de José Andrés Gómez e ilustrado por Juan Carlos Restrepo, publicado en 2017. 
los jóvenes participar en las investigaciones que buscan comprender lo que los jóvenes leen o no leen? En el estudio que realizamos en secundarias en México en 2014 Laura Guerrero, de la Universidad Iberoamericana, y yo hicimos partícipes a los jóvenes estudiantes para investigar cómo había cambiado la lectura en las últimas décadas ${ }^{3}$. Junto con ellos, creamos una breve lista de preguntas que les hicieron a un familiar o amigo y grabaron en audio. Luego entre todos analizamos las transcripciones y reflexionamos en torno a algunos de los cambios mencionados. Los jóvenes se entusiasmaron al poder participar como parte del equipo y se interesaron por el tema, contribuyendo a un rico debate acerca de los beneficios y perjuicios de la lectura en pantalla.

Más que nada, nos preocupó comprobar en esta investigación que sigue viva la visión simple de la lectura como una herramienta para el aprendizaje, para obtener información o "cultura", como dijeron algunos de los participantes. Esta visión es alimentada por los adultos que los rodean, que saben poco de lo que los jóvenes realmente leen o quieren leer.

La LIJ permite tomar riesgos, por ejemplo, acercarse a libros en lenguas desconocidas, pero que ayudan a conocer otras culturas, pensar en el lenguaje o en la traducción; acercarse a los libros sin palabras para invitar la lectura detenida de las imágenes y volverse coautor; acercarse a la tecnología digital para aprender qué tipo de historias se pueden crear, qué escriben los jóvenes en los miles de sitios de fan fiction y aprender del fenómeno de los booktubers. Todo ello permite también tratar temas difíciles y controversiales (abuso, violencia, xenofobia, muerte, discapacidad y sexualidad, por ejemplo) dentro de un espacio seguro, porque el lector puede tomar la distancia para leer y hablar de estos temas o hacer preguntas, así como también permite hacer conexiones entre distintas materias curriculares, por ejemplo, hablar de ciencia, biología, política o historia en la ciencia ficción o en las distopías para jóvenes.

Por supuesto que hay otros retos, como el afán por medir el conocimiento con exámenes y evaluaciones, lo cual limita la libertad de seleccionar y trabajar con detenimiento con ciertos textos o como el

Para mayor información se puede visitar el blog "Transformaciones lectoras" http://transformacioneslectoras.blogspot.com/2014/09/) 
acceso a textos de alta calidad literaria y estética. Aquí es donde los gobiernos pueden ayudar al ofrecer acervos seleccionados por expertos en LIJ a las escuelas. Los estudios muestran que para crear lectores, son importantes los libros atractivos, como también los espacios donde los lectores se encuentran con los autores e ilustradores, donde se pueda leer y dialogar con libertad y sea posible fomentar la empatía y la expresión emocional y estética con un acompañamiento adecuado y sensible a las necesidades de las nuevas generaciones de niños y jóvenes.

\section{Referencias bibliográficas}

Arizpe, Evelyn. "Entre imágenes y palabras: la investigación que promueve comunidades lectoras inclusivas y creativas". La literatura que acoge: inmigración y lectura de álbumes. Eds. Teresa Colomer y Martina Fittipaldi, Banco del LibroGRETEL y Fundación SM, 2012, pp. 44-68.

Arizpe, Evelyn, Colomer, Teresa \& Carmen Martínez-Roldán. Visual journeys through wordless narratives: An international inquiry with immigrant children and The Arrival. London, New York, Bloomsbury Academic, 2014.

Arizpe, Evelyn, Styles, Morag \& Shirley Brice Heath. "Reading lessons from the eighteenth century: Mothers, children and texts". Pied Piper Press, 2006. Recuperado de http://www.indiana. edu/ liblilly/janejohnson/reading-lessons-fulltext.pdf

Arizpe, Evelyn y Morag Styles. Lectura de imágenes. Los niños interpretan textos visuales. México, D.F., Fondo de Cultura Económica, 2004.

Bishop, Rudine Sims. "Mirrors, windows, and sliding glass doors". Perspectives, vol. 6 , no. 3, 1990, pp. ix-xi.

Colomer, Teresa. Andar entre libros. La lectura literaria en la escuela. México, D.F., Fondo de Cultura Económica, 2005.

García Moll, Luis, Amanti, Cathy, Neff, Deborah \& Norma González. "Funds of knowledge for teaching: Using a qualitative approach to connect homes and classrooms". Theory into Practice, vol. 31, no. 2, 1992, pp. 132-141.

Petit, Michèle. Leer el mundo. México, D.F., Fondo de Cultura Económica, 2015. 